\title{
Emotional memory impairments in a genetic rat model of depression: involvement of 5-HT/MEK/Arc signaling in restoration
}

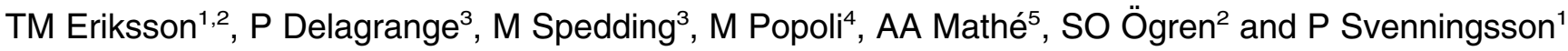 \\ ${ }^{1}$ Center of Molecular Medicine, Department of Physiology and Pharmacology, Karolinska Institute, Stockholm, Sweden; \\ ${ }^{2}$ Department of Neuroscience, Karolinska Institute, Stockholm, Sweden; ${ }^{3}$ Inst De Recherches Servier, Experimental Sciences, \\ Suresnes, France; ${ }^{4}$ Center of Neuropharmacology, Department of Pharmacological Sciences, Center of Excellence on \\ Neurodegenerative Diseases, University of Milan, Milan, Italy and ${ }^{5}$ Department of Clinical Neuroscience, Karolinska Institute, \\ Stockholm, Sweden
}

\begin{abstract}
Cognitive dysfunctions are common in major depressive disorder, but have been difficult to recapitulate in animal models. This study shows that Flinders sensitive line (FSL) rats, a genetic rat model of depression, display a pronounced impairment of emotional memory function in the passive avoidance (PA) task, accompanied by reduced transcription of Arc in prefrontal cortex and hippocampus. At the cellular level, FSL rats have selective reductions in levels of NMDA receptor subunits, serotonin $5-\mathrm{HT}_{1 \mathrm{~A}}$ receptors and MEK activity. Treatment with chronic escitalopram, but not with an antidepressant regimen of nortriptyline, restored memory performance and increased Arc transcription in FSL rats. Multiple pharmacological manipulations demonstrated that procognitive effects could also be achieved by either disinhibition of $5-\mathrm{HT}_{1 \mathrm{~A}} \mathrm{R} / \mathrm{MEK} / \mathrm{Arc}$ or stimulation of $5-\mathrm{HT}_{4} \mathrm{R} / \mathrm{MEK} / \mathrm{Arc}$ signaling cascades. Taken together, studies of FSL rats in the PA task revealed reversible deficits in emotional memory processing, providing a potential model with predictive and construct validity for assessments of procognitive actions of antidepressant drug therapies.
\end{abstract}

Molecular Psychiatry (2012) 17, 173-184; doi:10.1038/mp.2010.131; published online 18 January 2011

Keywords: antidepressant; BDNF; MAPK; passive avoidance; signal transduction; TrkB

\section{Introduction}

The clinical impact of emotional dysfunction on cognitive capacity is recognized but difficult to treat. ${ }^{1-3}$ Besides depressed mood, the DSM-IV criteria of major depressive disorder (MDD) involve cognitive aspects, that is, diminished ability to think and concentrate, or indecisiveness, with devastating effects on executive functions, short- and long-term learning and memory. ${ }^{2,3}$ These cognitive impairments appear to involve alterations in the neuronal processing of emotional stimuli, that is, negative attentional bias including feelings of worthlessness or excessive guilt and recurrent thoughts of suicide. ${ }^{4}$ Multiple brain areas, involved in emotionality and cognition, that is, prefrontal cortex (PFC), hippocampus (HPC), parahippocampal region (PHR), amygdala and striatum, show altered functions in MDD. ${ }^{1,2,5}$ In particular, volume reduction and impaired functionality of hippocampus have been repeatedly reported in MDD. ${ }^{2,6,7}$

Correspondence: Dr P Svenningsson, Center of Molecular Medicine, Department of Physiology and Pharmacology, Nanna Svartz väg 2, Karolinska Institute, Stockholm SE-171 77, Sweden. E-mail: Per.Svenningsson@ki.se

Received 26 April 2010; revised 27 November 2010; accepted 6 December 2010; published online 18 January 2011
Studies in depressed patients have linked dysfunction of the central serotonergic system with abnormal cognitive processing of emotional stimuli, and indicated that an important component in antidepressant therapy is support of cognitive functions, which can be separated from elevation of mood. ${ }^{8}$ The clinical efficacy of selective serotonin reuptake inhibitors (SSRIs) in MDD is exerted by several of the 14 cloned 5 -HT receptors, with $5-\mathrm{HT}_{1 \mathrm{~A}} \mathrm{R}$ being the most studied. ${ }^{9}$ Several studies have described alteration of $5-\mathrm{HT}_{1 \mathrm{~A}} \mathrm{R}$ in postmortem samples from patients with MDD. ${ }^{10-15}$ Interestingly, $5-\mathrm{HT}_{1 \mathrm{~A}} \mathrm{R}$ antagonists facilitate learning and counteract memory impairments. ${ }^{9}$ In addition, 5$\mathrm{HT}_{4} \mathrm{R}$ agonists may have antidepressant ${ }^{16}$ and procognitive effects in learning and memory tasks. ${ }^{17}$

The delayed onset of SSRIs and most other antidepressants implicate that therapeutic effects are mediated beyond elevations of monoamines, such as changes of receptor coupling to intracellular signaling cascades and cross talk with non-monoaminergic mechanisms. Several lines of evidence indicate that brain-derived neurotrophic factor (BDNF)-induced activation of TrkB mediate actions of antidepressants. ${ }^{18-21}$ TrkB receptors, in turn, stimulate several intracellular cascades including the mitogen-activated protein kinase (MAPK), AKT and phospholipase C 
pathways. $^{21,22}$ In particular, the MAPK pathway is involved in behavioral effects of antidepressants and an important modulator of ionotropic receptor signaling, structural remodeling and consolidation of fear memories. ${ }^{23-25}$ Synaptic activation of MAPK induces, via CREB and Elk-1, expression of activity-related cytoskeletal-associated protein (Arc/Arg 3.1). ${ }^{23,26-28}$ Arc expression is induced by long-term potentiationinducing stimuli, requiring NMDAR, ${ }^{27,29}$ involved in synaptic memory consolidation and enriched in hippocampal dendritic spines where its activation is required for acquisition of contextual and spatial learning. ${ }^{26,30,31}$ Arc expression is also activated by several other mechanism(s), including $\mathrm{BDNF},{ }^{28}$ protein kinase $A,{ }^{30}$ and pertussis-induced inhibition of $\mathrm{G}_{\mathrm{i}}$-mediated signaling. ${ }^{32}$ Accordingly, blockade of 5$\mathrm{HT}_{1 \mathrm{~A}} \mathrm{R}$ augments the effect of an acute dose of paroxetine on increasing transcription of Arc mRNA. ${ }^{33}$ Thus, Arc transcription may be a key nodal point in integration of monoaminergic antidepressant effects with glutamate-driven activity-dependent neuronal adaptations regulating gene transcription associated with information processing and associative learning.

The Flinders sensitive line (FSL) is a rat strain associated with distinct behavioral and neurochemical features of major depression, including face validity, that is, psychomotor retardation and increased rapid eye movement sleep. FSL rats display a genetic vulnerability to environmental stressors and have been successfully used for validation of antidepressant effects. ${ }^{34}$ Interestingly, promotion of hippocampal neuroplasticity, by means of intracerebroventricular injections of bone marrow mesenchymal stem cells, reverses the depressive-like phenotype of FSL rats. ${ }^{35}$ Long-term potentiation is also reduced in the cornu ammonis 1 (CA1) area of hippocampus, shown during in vivo recordings in anesthetized FSL rats $^{36}$ paralleled by reduced NR1 subunits of the NMDAR in hippocampal synaptosomes. ${ }^{36}$ FSL rats also have reduced hippocampal volume and dendritic spines, which is reversed by antidepressants. ${ }^{37}$ These alterations may affect emotional memory processes that, indeed, are believed to depend on enduring remodeling of neuronal morphology and activity-dependent structural plasticity, particularly of glutamatergic dendritic spines, indicating possible cognitive impairments in FSL rats.

In the present study, we performed behavioral, pharmacological, biochemical and histological experiments to examine whether FSL rats exhibit impairments in emotional learning, which may respond differentially to various antidepressant therapies and/or selective manipulations of 5-HT neurotransmission.

\section{Materials and methods}

Animals and pharmacological treatments

Adult FSL and Flinders resistant line (FRL) rats were bred at the Department of Physiology and Pharmacology at Karolinska Institute, and were tested at 2-4 months of age. Rats were kept in standard cages (TypeIV Macrolon, Bayer Material Science, Leverkusen, Germany, $26 \times$ $42 \times 15 \mathrm{~cm}$ ) with sawdust, at room temperature and relative humidity (45-55\%) under a constant light/dark cycle (lights on at 0700 hours). Water and food pellets (LactaminR36, Stockholm, Sweden) were available ad libitum. Experimental procedures were approved by the local Animal Ethics Committee (Stockholms Norra Djurförsöksetiska Nämnd).

FRL and FSL rats were randomly assigned to groups given either escitalopram, nortriptyline or vehicle administered to standard rat pellets ${ }^{38,39}$ (Supplementary Figure S4) (Lactamin AB). Escitalopram was given at $340 \mathrm{mg} \mathrm{kg}^{-1}$ pellets for 3 weeks, followed by $410 \mathrm{mg} \mathrm{kg}^{-1}$ pellets. Nortriptyline was administered at $330 \mathrm{mg} \mathrm{kg}^{-1}$ pellet.

NAD-299 ((R)-3-N,N-dicyclobutylamino-8-fluoro3,4-dihydro-2H-1-benzopyran-5-carboxamide hydrogen $(2 R, 3 R)$ tartrate monohydrate; $1 \mathrm{mg} \mathrm{kg}^{-1}$ subcutaneous (s.c.); AstraZeneca R\&D, Södertälje, Sweden) and RS67333 (1 $\mathrm{mg} \mathrm{kg}^{-1}$ intraperitoneal (i.p.); Tocris, Bristol, UK) were administered $30 \mathrm{~min}$ before testing. ${ }^{40,41}$ The ( \pm )-8-OH-DPAT (8-hydroxy-2-(di-n-propylamino)tetralin; $0.3 \mathrm{mg} \mathrm{kg}^{-1}$ s.c.; Sigma, St Louis, MO, USA) and MK-801 ( + )-10,11-dihydro-5-methyl$5 H$-dibenzo[a,d]-cyclohepten-5,10-imine hydrogen maleate; $0.05 \mathrm{mg} \mathrm{kg}^{-1}$ s.c.; Sigma) were both administered 15 min before training. ${ }^{41}$ GR125487 (5-fluoro-2methoxy-[1-[2-[(methylsulfonyl)amino]ethyl]-4-piperi dinyl]-1H-indole-3-methylcarboxylate sulfamate; $10 \mathrm{mg} \mathrm{kg}^{-1}$ i.p.; Tocris) was given $60 \mathrm{~min}$ before training. ${ }^{17}$ Drugs were dissolved in $2 \mathrm{ml} \mathrm{kg}^{-1}$ of $0.9 \%$ NaCl. PD184161(Servier, Suresnes, France) was administered $60 \mathrm{~min}$ before testing at a dose of $30 \mathrm{mg} \mathrm{kg}^{-1}$ i.p. and dissolved in 1\% Tween80 in $6 \mathrm{ml} \mathrm{kg}^{-1}$ of $0.9 \% \mathrm{NaCl}$.

\section{Passive avoidance, forced-swim test, open field and elevated plus-maze}

The step-through passive avoidance (PA) was performed as described earlier ${ }^{41}$ (see Supplementary Figure S1). During PA training, rats were placed in the bright compartment and allowed to explore for $120 \mathrm{~s}$. Thereafter, the sliding door was opened and once the rat had entered the dark compartment, the sliding door was automatically closed and a weak electrical stimulus $(0.4 \mathrm{~mA}, 2 \mathrm{~s}$ scrambled current) was delivered through the grid floor. After $24 \mathrm{~h}$, the animal was again gently placed in the light compartment, and the latency to enter the dark compartment with all four paws was automatically measured (retention latency) with a cutoff time for testing after $9 \mathrm{~min}$. See Supplementary information regarding the procedures for forced-swim test, open field and elevated plus-maze (Supplementary Figure S4).

\section{Histological measurements of Arc and BDNF transcription and 5-HT receptors}

For in situ hybridization experiments, rat brains were rapidly dissected after decapitation and immediately frozen at $-80^{\circ} \mathrm{C}$. Fresh frozen $(12 \mu \mathrm{m})$ coronal cryostat 
sections were prepared and hybridized with ${ }^{35} \mathrm{~S}$ radiolabeled antisense riboprobes against Arc and BDNF according to a previous protocol. ${ }^{42}$ For receptor autoradiography procedure with $\left[{ }^{3} \mathrm{H}\right] 8-\mathrm{OH}-\mathrm{DPAT}$, $\left[{ }^{125} \mathrm{I}\right]$ cyanopindolol and $\left[{ }^{3} \mathrm{H}\right] \mathrm{GR} 113808$, see Supplementary Figure S2. Densitometric measurements were obtained from autoradiograms using the $\mathrm{NIH}$ Image 1.40 software (National Institute of Mental Health, Bethesda, MD, USA) after subtraction of non-specific binding.

\section{Immunoprecipitation and immunoblotting of total protein, and their phosphorylation state}

The levels of the studied proteins and their phosphorylation state were assessed by immunoblotting. To preserve protein phosphorylation, rats were sacrificed using focused microwave irradiation (Muromachi Kikai, Tokyo, Japan), with brain regions dissected and frozen at $-80^{\circ} \mathrm{C}$. Alternatively, rats were decapitated, their head snap frozen, brain regions rapidly dissected out and processed to avoid dephosphorylation events. These procedures have been described earlier. ${ }^{42,43}$ For detailed immunoprecipitation and immunoblotting protocols, see Supplementary Table S1.

\section{Statistical analysis}

The data were analyzed with one-way or two-way analysis of variances, with drug treatment, rat strain or brain region as factors in multiple comparisons. For each significant F-ratio, Newman-Keuls test was used for post hoc comparison of effects following one-way analysis of variance, whereas Bonferroni post hoc test was used after two-way analysis of variance. When only two groups were compared (FRL with FSL), a two-tailed unpaired Student's $t$-test was used. $P<0.05$ was considered statistically significant.

\section{Results}

Baseline performance in PA and Arc transcription in FSL and FRL rats

FSL rats of both sexes displayed reduced performance in the PA task compared with the control FRL rats (Figure 1a). To determine biochemical measures corresponding to the deficit in contextual memory, assessment of Arc mRNA levels was made in several brain regions. Arc mRNA expression was specifically reduced in medial PFC and in hippocampal CA1 and dentate gyrus subterritories, but not in parahippocampus, somatosensory cortex, amygdala or thalamus (Figures 1d-m).

\section{Baseline regulation of glutamate and 5-HT receptors and signaling molecules}

Arc mRNA expression is regulated by glutamate and serotonin neurotransmission, and, in accordance with reduced Arc mRNA, western blotting showed lower levels of NR1 subunits of the NMDAR complex in PFC, hippocampus and parahippocampus of FSL rats
(Figure 2a). The compositions of the different NMDAR subunits determine gating and kinetic properties of the NMDAR, with important consequences for synaptic plasticity and memory. ${ }^{44,45}$ The NR2B subunit is specifically involved in NMDAR interactions with the MAPK cascade. $^{46}$ In FSL rats, NR2A and NR2B subunits were specifically lowered in PFC and hippocampus (Figure 2a). In none of the studied regions, GluR1 subunits of the AMPAR complex were different between FSL and FRL rats (Figure 2a). Serotonin $5-\mathrm{HT}_{1 \mathrm{~A}} \mathrm{R}$, but not $5-\mathrm{HT}_{1 \mathrm{~B}} \mathrm{R}$ or $5-\mathrm{HT}_{4} \mathrm{R}$, were reduced in all studied regions in FSL rats (Figure 2a). Likewise, labeling of $5-\mathrm{HT}_{1 \mathrm{~A}} \mathrm{R}$ by $\left[{ }^{3} \mathrm{H}\right] 8-\mathrm{OH}-\mathrm{DPAT}$ was reduced in hippocampal sections from male (Supplementary Figure S2A-C) and female (Supplementary Figure S2A, D and E) FSL rats, whereas there were no alterations in $5-\mathrm{HT}_{1 \mathrm{~B}} \mathrm{R}-$ or 5 $\mathrm{HT}_{4} \mathrm{R}$-like binding using $\left[{ }^{125} \mathrm{I}\right]$ cyanopindolol and $\left[{ }^{3} \mathrm{H}\right] \mathrm{GR} 113808$, respectively (Supplementary Figure $\mathrm{S} 2 \mathrm{~F}-\mathrm{O})$.

In contrast to the reduced levels of NMDAR subunits, their phosphorylation states appeared to be generally increased in FSL rats, possibly as a compensatory mechanism(s). Specifically, NR1 subunits showed significantly increased phosphorylation of Ser $^{896}$, a PKC site, and Ser $^{897}$, a protein kinase A site, in the hippocampus (Figure 2b). In prefrontal cortices, the phosphorylation at the NR1 subunit at site Ser $^{896}$ was increased, and the NR2A subunit exhibited an increased phosphorylation at $\operatorname{Ser}^{1232}$, a cdk5 site (Figure 2b). The phosphorylation states of NR2B subunits at Ser ${ }^{1303}$, a CaMKII site, and $\mathrm{Tyr}^{1472}$, a SRC tyrosine kinase site, were not altered in FSL rats (Figure 2b). The phosphorylation levels of GluR1 subunits at Ser $^{831}$, a PKC/CaMKII site, and Ser $^{845}$, a protein kinase A site, were not altered (Figure 2b). The total levels of MEK, p42-MAPK and p44-MAPK were increased in PFC and hippocampus of FSL rats (Figure 2c). No changes in the phosphorylation of Ser $^{217 / 221}$-MEK were found (Figure 2d). However, reduced phosphorylations at $\mathrm{Thr}^{183 / \mathrm{Ty} 185}-\mathrm{p} 42$ and $\mathrm{Thr}^{202 / \mathrm{Tyr} 204}$-p44 in hippocampus were found, indicative of a reduced MEK activity in FSL rats (Figure 2d). In contrast, total levels or phosphorylation states of CaMKII, GSK-3 $\beta$, AKT or in PSD-95, a postsynaptically enriched protein, were not altered (Figures 2c and d). These data suggest that MEK/MAPK signaling is particularly dysregulated in FSL rats and that decreased MEK activity, perhaps related to reduced NMDAR and 5-HT receptor-mediated transmission, parallels with memory impairments and reduced Arc mRNA expression in FSL rats.

Impairing effect on PA performance by NMDAR blockade in both FSL and FRL rats

NMDAR are critically implicated in the acquisition and consolidation of several types of memories including the PA task. ${ }^{9}$ In agreement with previous reports, treatment with an amnesic dose of MK-801, a non-competitive NMDAR antagonist, of FRL rats severely disrupted retention performance, mimicking 

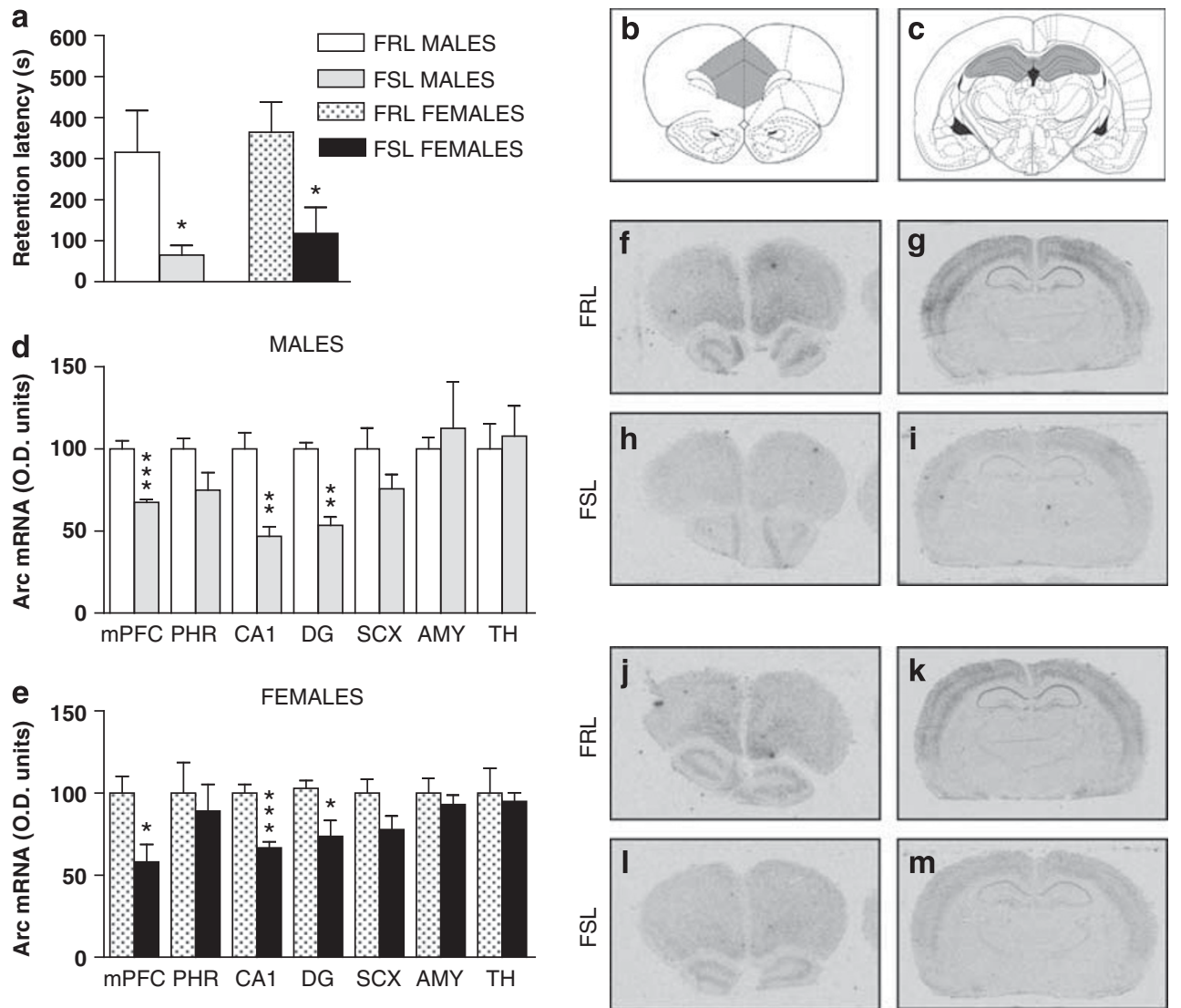

Figure 1 Male and female Flinders sensitive line (FSL) rats display emotional memory impairments and reduction of Arc mRNA expression specifically in brain regions implicated in cognitive processing. Passive avoidance (PA) emotional memory performance under baseline conditions in male $(n=6-8$ per group) and female ( $n=11$ per group) Flinders resistant line (FRL) and FSL rats (a). Effects on step-through latency at the retention test performed $24 \mathrm{~h}$ after PA training. Atlas diagrams illustrating coronal sections of mPFC (b) and hippocampal subregions (c). Histograms of Arc mRNA in four to five male (d) and five female (e) FRL and FSL rats per group. Autoradiograms from in situ hybridization experiments against Arc mRNA in male FRL (f, $\mathbf{g})$ and FSL $(\mathbf{h}, \mathbf{i})$ rats or female FRL $(\mathbf{j}, \mathbf{k})$ and FSL $(\mathbf{l}, \mathbf{m})$ rats. AMY, amygdaloid nuclei; CA1, cornu ammonis 1 of hippocampus; DG, dentate gyrus of hippocampus; mPFC, medial prefrontal cortex; PHR, parahippocampal region; SCX, primary sensory cortex; TH, thalamic nuclei. Data represent mean \pm s.e.m. ${ }^{*} P<0.05$; ${ }^{* *} P<0.01 ;$ and $* * * P<0.001$ versus corresponding FRL control group.

the memory impairments seen in FSL rats (Supplementary Figure S3 and summary Supplementary Figure S7A-C).

Effects of escitalopram and nortriptyline on behavioral performance in PA, forced-swim test, open field, elevated plus-maze and transcription of Arc

To test whether the impairment in memory performance in FSL rats could be reversed by antidepressants, FSL and FRL rats were treated chronically with vehicle, escitalopram or nortriptyline. ${ }^{38,39}$ In FSL rats, escitalopram, but not nortriptyline, reversed the impairment of memory performance in the PA test (Figure 3a). In contrast, escitalopram was without effect on memory performance in FRL rats, comparable to lack of effects of paroxetine in Sprague-Dawley rats ${ }^{47}$ whereas nortriptyline impaired performance (Figure 3a). Escitalopram, but not nortriptyline, specifically increased expression of Arc mRNA in the CA1 and dentate gyrus subregions of hippocampus of FSL rats (Figures $3 \mathrm{~b}-\mathrm{e}$ ).
Escitalopram reduced immobility in the forced-swim test in FSL rats. ${ }^{38}$ Similarly, nortriptyline decreased immobility of FSL rats in the forced-swim test (Supplementary Figure S4A) via mechanisms unrelated to alterations in locomotion (Supplementary Figure S4B and C). Notably, the differential effect of escitalopram and nortriptyline in the PA test could not be correlated to elevated plus-maze performance, as both agents induced anxiolytic-like effects in control FRL rats (Supplementary Figure S4D and E). FSL rats displayed a basal anxiolytic phenotype and nortriptyline was without effect, whereas escitalopram further reduced anxiety-like behavior (Supplementary Figure S4D and E).

Measurements of BDNF mRNA and protein, and phosphorylated TrkB under baseline conditions and following escitalopram and nortriptyline

Several antidepressant actions are mediated via BDNF and its predominant receptor TrkB, and BDNF 

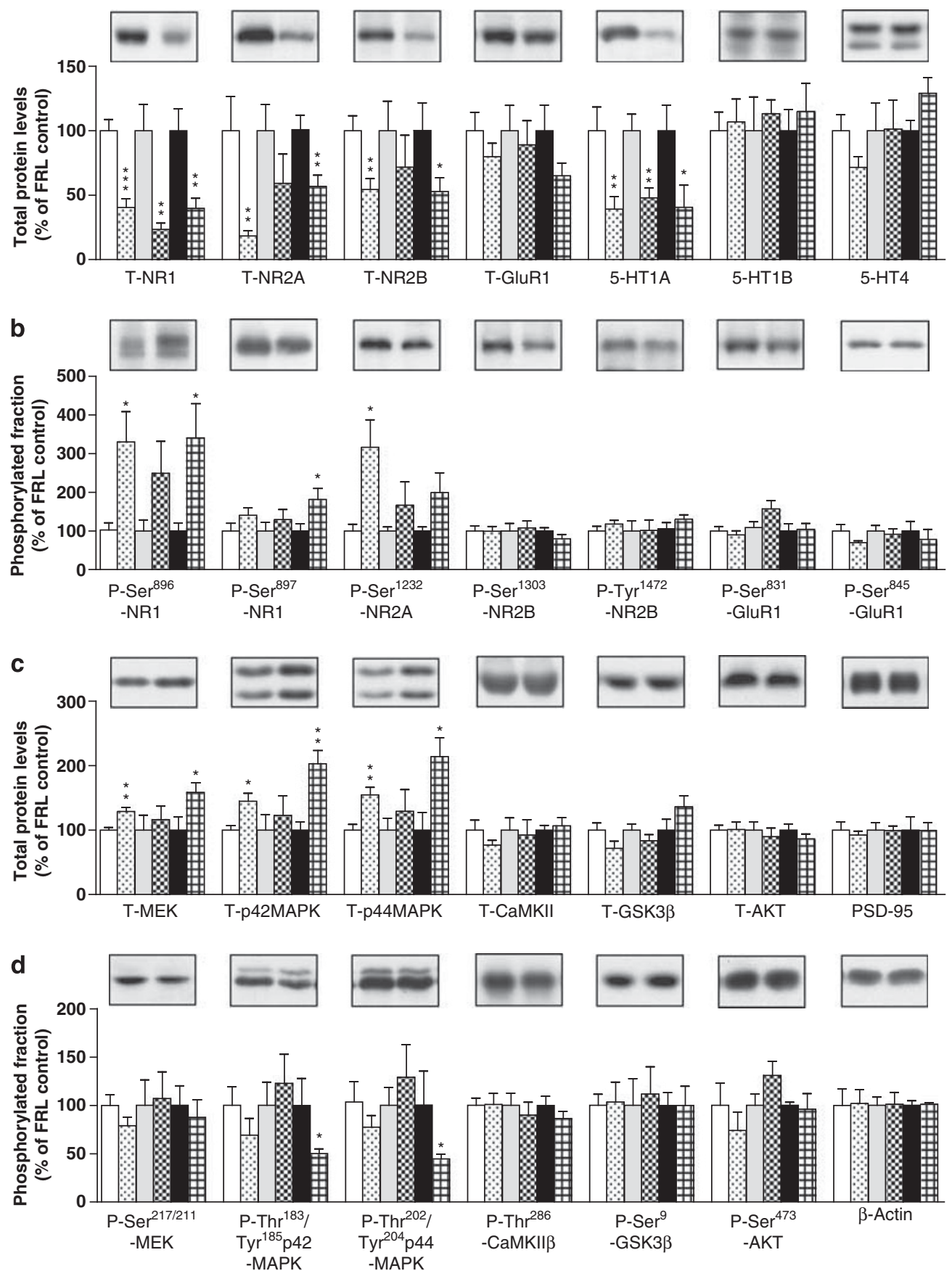

Figure 2 Alterations of total proteins and phosphorylated forms of proteins in Flinders sensitive line (FSL) rats compared with Flinders resistant line (FRL) control rats. Top, illustration of labeling of bars. Histograms of quantification of total protein levels (a, c) and phosphorylated form of the protein normalized to the total level of the same protein (b, d) in prefrontal cortex (PFC), parahippocampal region (PHR) and hippocampal region (HPC). Representative western blots from hippocampal region are shown above each histogram. Values are mean \pm s.e.m. from four to eight animals per group. ${ }^{*} P<0.05 ;{ }^{*} P<0.01$; and ${ }^{*}{ }^{*} P<0.001$ versus corresponding FRL control group.

signaling is reflected by the phosphorylation state of TrkB. ${ }^{18-22}$ BDNF signaling increases Arc mRNA and protein expression in neurons, ${ }^{28}$ and could potentially act upstream of Arc under baseline conditions and/or following escitalopram treatment in FSL rats.
Immunoblotting revealed regional-specific differences of basal proBDNF, with reduced levels in the hippocampus of FSL rats when compared with FRL rats, but increased levels in the parahippocampal region and unaltered levels in the PFC (Supplementary Figure 


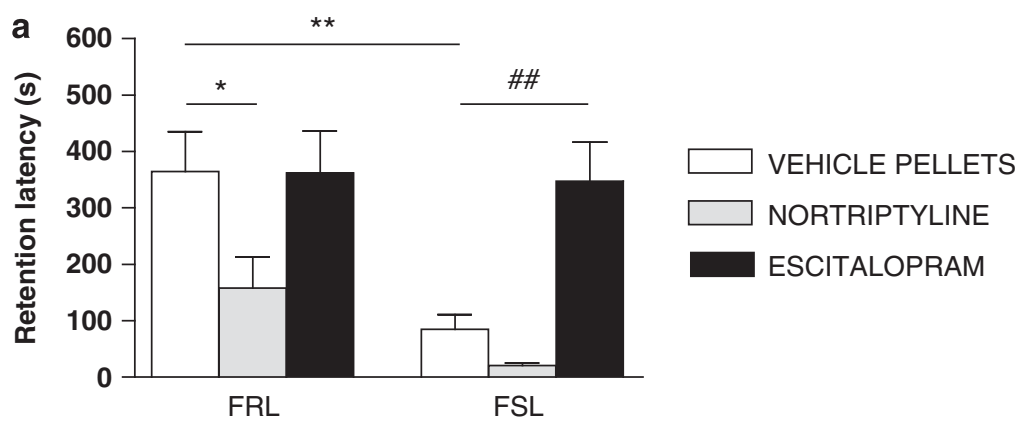

VEHICLE PELLETS

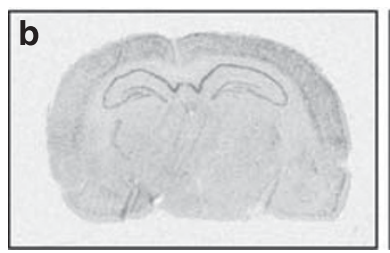

NORTRIPTYLINE

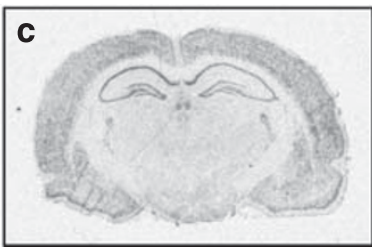

ESCITALOPRAM

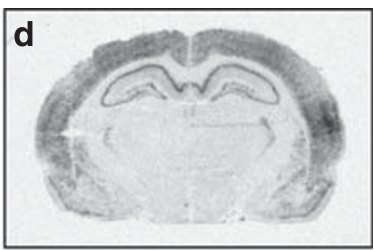

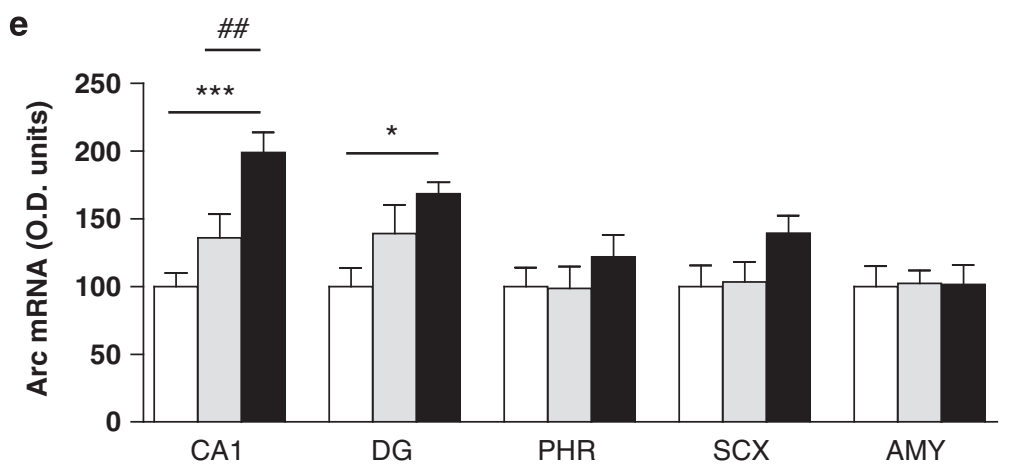

Figure 3 Differential effect of escitalopram and nortriptyline in restoration of emotional memory impairments and Arc transcription in Flinders sensitive line (FSL) rats. Effects on step-through latency at the retention test performed $24 \mathrm{~h}$ after passive avoidance training in male Flinders resistant line (FRL) and FSL rats ( $n=9-12$ per group) (a). Autoradiograms from in situ hybridization experiments against Arc mRNA in rats receiving vehicle pellets (b), chronic nortriptyline (c) and chronic escitalopram (d). Histograms of quantification of the effects of antidepressants on Arc mRNA in six male FSL rats per group (e). AMY, amygdaloid nuclei; CA1, cornu ammonis 1 of hippocampus; DG, dentate gyrus of hippocampus; PHR, parahippocampal region; SCX, primary sensory cortex. Data represent mean \pm s.e.m. ${ }^{*} P<0.05 ;{ }^{* *} P<0.01 ;{ }^{* *} P<0.001$ versus corresponding FRL control group; (a) ${ }^{\# \# P}<0.01$ FSL versus escitalopram; and (e) ${ }^{\#} P<0.01$ nortriptyline versus escitalopram.

S5A). However, basal levels of mature BDNF, as well as total and phosphorylated TrkB, did not differ between the genotypes in the examined regions (Supplementary Figure S5A and B).

In response to both escitalopram and nortriptyline, FSL rats showed increased expression of BDNF mRNA in the dentate gyrus, but not in the CA1, of hippocampus (Supplementary Figure S5C-F). In comparison, no significant alterations of proBDNF or BDNF proteins were found in total hippocampal or parahippocampal homogenates from antidepressanttreated animals (Supplementary Figure S5G). Nortriptyline and escitalopram induced treatment-, region- and site-specific changes of TrkB phoshorylation, without affecting total TrkB. Specifically, both nortriptyline and escitalopram increased phosphorylation of TrkB at $\mathrm{Tyr}^{816}$, whereas nortriptyline, but not escitalopram, increased phoshorylation at $\mathrm{Tyr}^{705}$
TrkB, and none of these treatments regulated $\mathrm{Tyr}^{515}$ TrkB in hippocampus (Supplementary Figure S5H). No corresponding alterations were found in the parahippocampal region (Supplementary Figure $\mathrm{S} 5 \mathrm{H})$. It should be noted that the antisera toward phosphorylated TrkB can also detect phosphorylated TrkA, and both TrkB and TrkA are found in hippocampal extracts (Supplementary Figure S6A and B). In view of this, immunoprecipitations of TrkB were done from hippocampal brain tissue and, subsequently, analyzed for total TrkA and TrkB receptors as well as phosphorylated TrkB (Supplementary Figure S6C-E). No TrkA was found in TrkB immunoprecipitates (Supplementary Figure S6E). However, immunoreactivity of the antidepressantresponsive $\mathrm{Tyr}^{816}$-TrkB site was readily detected in TrkB immunoprecipitates (Supplementary Figure S6D). In response to treatment with escitalopram 
a
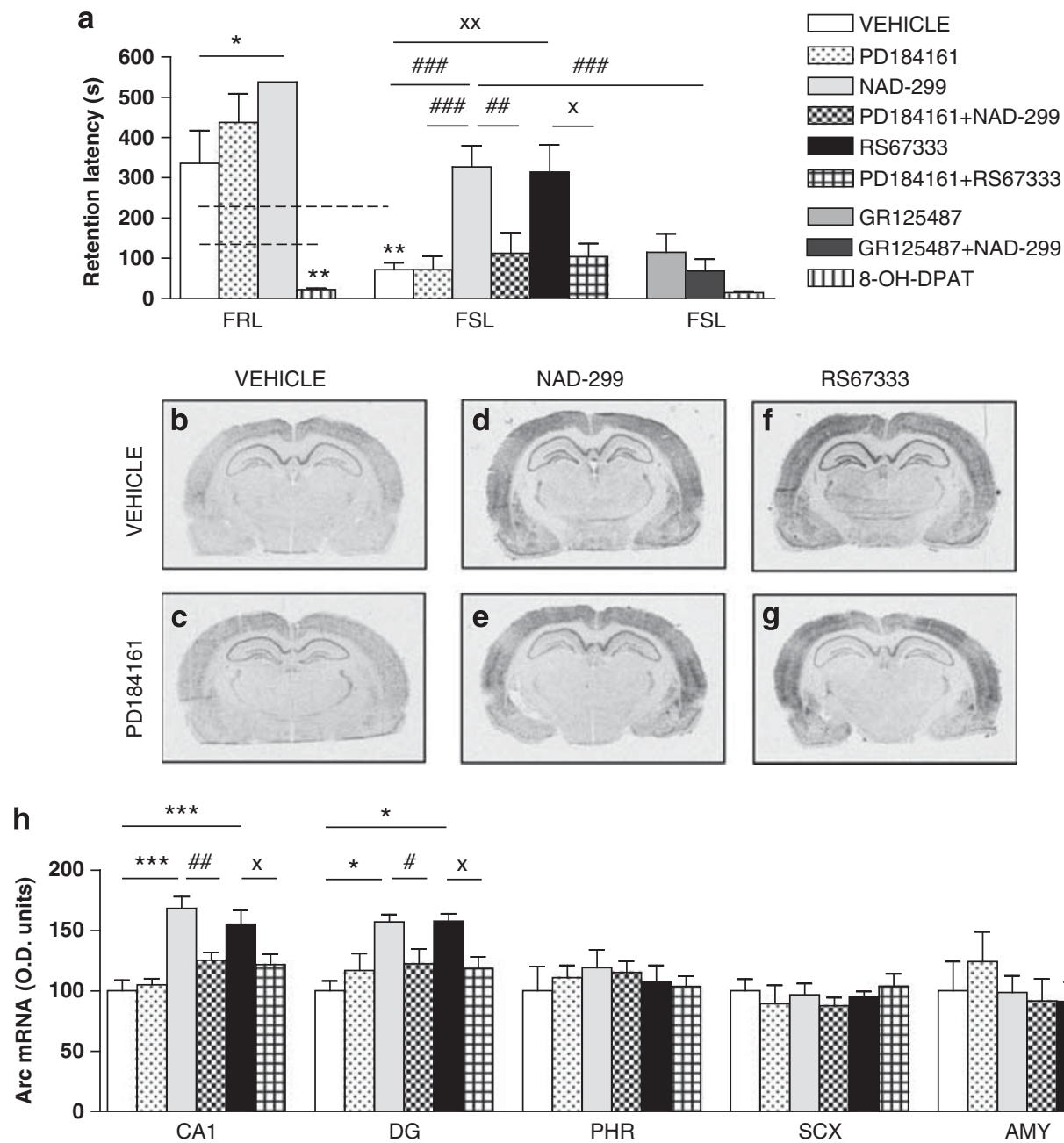

$D G$

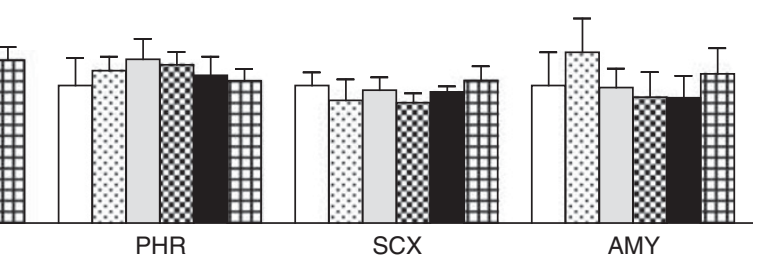

Figure 4 Effects of $5-\mathrm{HT}_{1 \mathrm{~A}} \mathrm{R}$ or $5-\mathrm{HT}_{4} \mathrm{R}$ agonists and antagonists, and involvement of MEK activity in restoration of emotional memory function and induction of Arc mRNA expression. Passive avoidance memory performance assessed by step-through latency at the retention test performed $24 \mathrm{~h}$ after training in male Flinders resistant line (FRL) and Flinders sensitive line (FSL) rats ( $n=7-18$ per group) (a). The lack of error bar for FRL rats treated with NAD-299 ((R)-3- $N, N$ dicyclobutylamino-8-fluoro-3,4-dihydro-2H-1-benzopyran-5-carboxamide hydrogen (2R,3R)tartrate monohydrate) was because of that none of the rats returned to the conditioned compartment at testing. Autoradiograms from in situ hybridization experiments against Arc mRNA in rats receiving 5-HT ligands alone (upper row) or pretreatment with MEK inhibitor (lower row) or vehicle (b, c), $5-\mathrm{HT}_{1 \mathrm{~A}} \mathrm{R}$ antagonist (d, e) or 5- $\mathrm{HT}_{4} \mathrm{R}$ agonist (f, g). Primary mechanisms of action: PD184161-MEK inhibitor; NAD-299-5- $\mathrm{HT}_{1 \mathrm{~A}} \mathrm{R}$ antagonist; RS67333-5- $\mathrm{HT}_{4} \mathrm{R}$ agonist; GR125487-5-HT $\mathrm{R}_{4}$ antagonist; and 8-OH-DPAT (8-hydroxy-2-(di- $n$-propylamino)tetralin)- $5-\mathrm{HT}_{1 \mathrm{~A}} \mathrm{R}$ agonist. Histograms of quantification of the effects on Arc mRNA transcription in six male FSL rats per group (h). AMY, amygdaloid nuclei; CA1, cornu ammonis 1 of hippocampus; DG, dentate gyrus of hippocampus; PHR, parahippocampal region; SCX, primary sensory cortex. Data represent mean \pm s.e.m. ${ }^{*} P<0.05 ;{ }^{*} P<0.01 ;{ }^{* *} P<0.001$ versus corresponding FRL control group; ${ }^{\# \#} P<0.01 ;{ }^{* \#} P<0.01$ versus FSL NAD-299; and X $P<0.05$ versus FSL RS67333.

and nortriptyline, levels of Tyr ${ }^{816}$-TrkB were increased in hippocampal TrkB immunoprecipitates (Supplementary Figure S6D, F). Vice versa, in a confirmatory experiment, immunoprecipitation of $\mathrm{Tyr}^{816}$-TrkB resulted in higher levels of TrkB immunoreactivity in antidepressant-treated rats (Supplementary Figure S6C). Notably, no TrkA was found in Tyr ${ }^{816}$-TrkB immunoprecipitates (Supplementary Figure S6E), indicating that phosphorylation at this site in hippocampus occurs mainly at TrkB.
Effects of selective $5-\mathrm{HT}_{1 A} \mathrm{R}$ and $5-\mathrm{HT}_{4} \mathrm{R}$ ligands, with and without a MEK inhibitor, on PA performance and transcription of Arc

Based on the procognitive effects of escitalopram in the PA test in FSL rats and reduced $5-\mathrm{HT}_{1 \mathrm{~A}} \mathrm{R}$ levels, we studied 5-HT receptor subtypes in modulating memory performance in FSL rats. The $5-\mathrm{HT}_{1 \mathrm{~A}} \mathrm{R}$ agonist 8-OH-DPAT impaired performance in the PA test in FRL rats (Figure 4a). On the other hand, NAD299, a $5-\mathrm{HT}_{1 \mathrm{~A}} \mathrm{R}$ antagonist, enhanced performance in 
the PA test in FRL rats and reversed the memory dysfunction in the FSL rats, reminiscent of the action of escitalopram (Figure 4a). Inhibition of presynaptic $5-\mathrm{HT}_{1 \mathrm{~A}} \mathrm{R}$ causes an increase in the firing rate of serotonin neurons, whereas inhibition of postsynaptic $5-\mathrm{HT}_{1 \mathrm{~A}} \mathrm{R}$ causes a decrease of inhibitory serotonin transmission in specific circuits. ${ }^{9}$ Next, we pretreated the rats with a $5-\mathrm{HT}_{4} \mathrm{R}$ antagonist, known to mediate its actions at the postsynaptic site. GR125487 at a concentration where it had no intrinsic effect blocked the effect of NAD-299, indicating that NAD-299 exerts, at least, some of its effects via stimulation of $5-\mathrm{HT}_{4} \mathrm{R}$ (Figure 4a). The 5- $\mathrm{HT}_{4} \mathrm{R}$ agonist, RS67333, also restored memory performance in the PA test (Figure 4a). Both 5- $\mathrm{HT}_{1 \mathrm{~A}} \mathrm{R}^{9,48}$ and $5-\mathrm{HT}_{4} \mathrm{R}^{49,50}$ have been shown to regulate the MEK/MAPK cascade, and as the biochemical data indicated that MEK/MAPK signaling is altered in FSL rats (Figures 2c and d), we investigated whether the MEK/MAPK signaling cascade is mediating procognitive actions of NAD-299 and/or RS67333. Rats were pretreated with a MEK inhibitor, PD184161, ${ }^{24}$ at a dose where it had no intrinsic effect, before treatment with either NAD-299 or RS67333. PD184161 completely blocked the enhancing effects of NAD-299 or RS67333 in the PA test (Figure 4a).

We also found that NAD-299 and/or RS67333 could mimic the region-specific stimulatory effects of escitalopram on Arc mRNA in the CA1 and dentate gyrus subregions of hippocampus (Figures $4 \mathrm{~d}$, $\mathrm{f}$ and $\mathrm{h}$ ). Moreover, although PD184161 had no effects by itself on Arc transcription in FSL rats (Figures 4c and h), it significantly counteracted the actions of both NAD299 and RS67333 on Arc mRNA (Figures 4e, g and h). It seems that MEK/MAPK signaling is a nodal point in mediating some behavioral and biochemical postsynaptic serotonergic effects that are critically involved in procognitive effects in the PA paradigm.

\section{Discussion}

A substantial proportion of depressed patients exhibits deficits in several memory tasks, including declarative verbal and recollection memory, executive functions and emotional word processing. ${ }^{2,6,8,14,21,51,52}$ Improvement of cognitive processing and emotional memory function in depression is believed to be important for the treatment outcome in MDD. ${ }^{2,4}$ In the present study, we provide data indicating that the genetic FSL rat line of depression may be utilized as a model for studies of reversible impairments in emotional processing and memory, displaying predictive validity for assessment of drugs supporting cognitive performance. ${ }^{4,53}$ The impairments of memory performance are in accordance with the findings of reduced Arc mRNA specifically in cortical and hippocampal subregions of FSL rats (Figures $1 \mathrm{~d}-\mathrm{m}$ ), consistent with accumulating data indicating that Arc transcription is activated by neuronal stimuli particularly important for encoding of one-trial hippocampal-dependent learning and long-term neuroplasticity involved in consolidation of memories. ${ }^{26,27,31,54}$

The marked alterations of glutamatergic receptors in the FSL rat line (Figure 2a, b) agree with a number of neuroimaging and postmortem histological studies showing glutamatergic abnormalities in MDD, ${ }^{55,56}$ for example, magnetic resonance spectroscopy studies in patients with MDD demonstrated altered glutamate levels in several cortical subregions. ${ }^{57-59}$ Accordingly, NMDAR binding and subunits are decreased in cortical regions in depressed patients. ${ }^{60-64}$ Similarly, the core NR1 subunit of the NMDAR was markedly reduced in FSL rats in the PFC, PHR and HPC extracts, accompanied with reductions also of the NR2A and NR2B subunits in the PFC and hippocampus (Figure 2a). Selective reductions of several NMDAR subunits in corticolimbic brain regions in FSL rats further indicate that these alterations have severe consequences for synaptic plasticity and account for the impairments of long-term potentiation in FSL rats. ${ }^{36}$ Consistent with findings reported from MDD patients, ${ }^{55,56}$ we observed only modest alterations of GluR1 levels. The phosphorylation state of NMDAR and AMPAR correlates with changes in synaptic strength. ${ }^{65}$ Despite the lower levels of NMDAR subunits found in FSL rats, phosphorylation levels were upregulated in several cases. Taken together, rather than subtype-specific alterations, regional-specific overall reductions of NMDAR partially compensated by hyperphosphorylation were found in FSL rats.

The specific reductions of $5-\mathrm{HT}_{1 \mathrm{~A}} \mathrm{R}-$, but not 5 $\mathrm{HT}_{1 \mathrm{~B}} \mathrm{R}$ - or 5- $\mathrm{HT}_{4} \mathrm{R}$-like binding, using immunoblotting (Figure 2a) and autoradiography receptor binding in FSL rats (Supplementary Figure S2A-O) agree with a previous study ${ }^{66}$ The reduction of $5-\mathrm{HT}_{1 \mathrm{~A}} \mathrm{R}$ are consistent with several neuroimaging studies and postmortem data from patients with MDD. ${ }^{10-14}$ It has, however, been difficult to distinguish primary effects and confounders in view of variations of $5-\mathrm{HT}_{1 \mathrm{~A}} \mathrm{R}$ binding during onset and remission of depression, responses to antidepressants, differences in agonist versus antagonist labeling, with the mixed results most likely also reflecting the clinical heterogeneity of depressed patients, drug treatment and/or aging. ${ }^{12,14,15}$

After chronic antidepressant treatments, a discrepancy was found between escitalopram and nortriptyline on both behavioral outputs and on Arc mRNA expression (Figures 3a-e). The restoring effects on Arc transcription and emotional memory performance of FSL rats are consistent with clinical findings supporting a serotonergic component in recovery of cognitive aspects. ${ }^{4,8,67}$ Indeed, these results in FSL rats show predictive and face validity with data on clinical efficacy for escitalopram and nortriptyline, antidepressants that have been reported to be similar on three conventional depression-rating scales, but differentiate in a superior improvement of cognitive symptoms by escitalopram, whereas nortriptyline rather improved neurovegetative symptoms. ${ }^{68}$ Calculation of a proportional impairment ratio 
in humans were found to be three- to ninefold higher for tricyclic antidepressants, than those reported for escitalopram, on a range of different psychometric tests for cognitive symptoms. The varying druginduced cognitive impairment caused by tricyclic agents is attributed to their anticholinergic and antihistaminergic properties, decreasing cognitive performance and arousal, respectively. ${ }^{67}$

Consistent with previous reports on antidepressant regimens, both escitalopram and nortriptyline increased BDNF mRNA in the dentate gyrus, but not CA1, of hippocampus (Supplementary Figure S5CF). ${ }^{20,21,69}$ We could not detect any corresponding effects on protein levels of proBDNF and mature BDNF (Supplementary Figure S5G). As discussed previously (for reviews, see Martinowich et al., ${ }^{20}$ Pittenger and Duman, ${ }^{21}$ and Castrén and Rantamäki ${ }^{69}$ ), a discrepancy between mRNA and protein expression of BDNF as found here may be due to several factors, including the omission of subregional analysis of hippocampal BDNF protein, retrograde/anterograde transport of BDNF protein transcribed in the dentate gyrus and the lack of distinct measures of intra- and extracellular BDNF protein.

BDNF-mediated signaling can be studied by measures of the phosphorylation state of the TrkB receptor. Binding of BDNF to the TrkB receptor induces its autophosphorylation at $\mathrm{Tyr}^{705}-\mathrm{TrkB}$ in the catalytic domain, which subsequently regulates the phosphorylation state at other tyrosine residues including Tyr ${ }^{515}$-TrkB, a Shc-binding site, and Tyr ${ }^{816}$ TrkB, a phospholipase C $\gamma 1$-binding site. ${ }^{69}$ The latter phosphorylation site of TrkB is also regulated via transactivation by G-protein-coupled receptors, independent of BDNF. ${ }^{70}$ In agreement with Rantamäki et $a{ }^{18}{ }^{18}$ and Saarelainen et al. ${ }^{19}$ we found that both a tricyclic antidepressant, nortriptyline, and a SSRI, escitalopram, increased phosphorylation at the phospholipase $\mathrm{C} \gamma 1$-binding site $\mathrm{Tyr}^{816}$-TrkB, but not at the Shc-binding site $\mathrm{Ty}^{515}$-TrkB in hippocampus (Supplementary Figure S5H). It is interesting that studies with phosphomutant TrkB mice have shown that the phospholipase $\mathrm{C} \gamma 1$-binding site is more important for synaptic plasticity than the Shc-binding site,$^{71}$ suggesting that the observed activation of $\mathrm{Tyr}^{816}$-TrkB by nortriptyline and escitalopram may be of functional significance in mediating long-term antidepressant actions. As the antisera toward phosphorylated TrkB can also detect phosphorylated TrkA and both these receptors are found in hippocampus (Supplementary Figure S6A and B), we performed additional experiments to confirm that antidepressants specifically increase phosphorylation at $\mathrm{Tyr}^{816}$ of TrkB. Indeed, in reciprocal immunoprecipitation experiments with antisera toward either TrkB or $\mathrm{Tyr}^{816}-\mathrm{TrkB}$, both nortriptyline and escitalopram increased $\mathrm{Tyr}^{816}$ specifically at TrkB, without regulating TrkA (Supplementary Figure S6C-F). Using direct immunoblotting from snap frozen hippocampi, we also found that nortriptyline, but not escitalopram, increased $\mathrm{Tyr}^{705}$ TrkB at the studied time point, suggesting a more sustained and/or stronger activation of TrkB by nortriptyline (Supplementary Figure $\mathrm{S} 5 \mathrm{H}$ ). However, it should be noted that we sacrificed the rats during daytime when they consumed less drug-containing pellets, and previous work has demonstrated that the autophosphorylation at $\mathrm{Tyr}^{705}-\mathrm{TrkB}$ is transient and most pronounced within $1 \mathrm{~h}$ after an injection of a tricyclic or a SSRI antidepressant. ${ }^{18,19}$

Taken together, the increased BDNF transcription and $\mathrm{Tyr}^{816}$-TrkB phosphorylation by both nortriptyline and escitalopram in FSL rats correlate well with the antidepressant and anxiolytic effects of these agents, but not with the differential effects on recovery of emotional memory in the PA paradigm. On the other hand, the discrepancy of nortriptyline and escitalopram on Arc transcription corresponds better with their effects on PA memory performance. Arc, rather than BDNF, transcription was therefore chosen as a biochemical correlate in the mechanistic studies on serotonin-mediated modulation of PA using selective ligands. However, it should be noted that a contribution of BDNF/TrkB signaling to the effects of escitalopram on Arc transcription and PA performance cannot be excluded.

Given the restoring effects of escitalopram on PA in FSL rats and the alterations of $5-\mathrm{HT}_{1 \mathrm{~A}} \mathrm{R}$ levels, we went on to investigate the effects of pharmacological modulation of specific 5-HT receptor subtypes. Stimulation of $5-\mathrm{HT}_{1 \mathrm{~A}} \mathrm{R}$ impairs learning and memory functions in a range of rodent cognitive tasks. ${ }^{9}$ This agrees with the pharmacological response to the $5-\mathrm{HT}_{1 \mathrm{~A}} \mathrm{R}$ agonist 8-OH-DPAT in FRL rats (Figure 4a and Supplementary Figure S7D), resembling the impaired memory performance of untreated FSL rats compared with control FRL rats (Figures 4a, 5a and b). The blunted response of FSL rats to 8-OH-DPAT is consistent with the findings of reduced postsynaptic $5-\mathrm{HT}_{1 \mathrm{~A}} \mathrm{R}$ density (Figure 2a). Conversely, the $5-\mathrm{HT}_{1 \mathrm{~A}} \mathrm{R}$ antagonist NAD-299 facilitates several types of learning in rodents, attributed to alleviation of $5-\mathrm{HT}_{1 \mathrm{~A}}$ R-activated $G_{i / o}$-mediated signaling cascades in postsynaptic neurons (Figure 4a). ${ }^{9,41}$ Thus, the effects of blockade of pre- and postsynaptic $5-\mathrm{HT}_{1 \mathrm{~A}} \mathrm{R}$ resembled the effects of increased 5 -HT function by escitalopram (Figures 3a and 5c). Despite an important role of $5-\mathrm{HT}_{1 \mathrm{~A}} \mathrm{Rs}$ in modulation of SSRI efficacy, chronic fluoxetine still has antidepressant-like effects in 5$\mathrm{HT}_{1 \mathrm{~A}} \mathrm{R} \mathrm{KO}$ mice, emphasizing an involvement of other 5-HT receptor subtypes. ${ }^{72}$ Intriguingly, the 5$\mathrm{HT}_{4} \mathrm{R}$ antagonist GR125487 blocked the facilitatory effects of NAD-299 on PA performance (Figure 4a), indicating that activation of postsynaptic $5-\mathrm{HT}_{4} \mathrm{Rs}$ is necessary for the restoring effect of $5-\mathrm{HT}_{1 \mathrm{~A}} \mathrm{R}$ antagonism on PA performance in FSL rats. Likewise, direct agonist stimulation of $5-\mathrm{HT}_{4} \mathrm{R}$ with RS67333 also restored PA performance (Figure 4a). Thus, these data indicate that not only does $5-\mathrm{HT}_{1 \mathrm{~A}} \mathrm{R}$ antagonism disinhibit postsynaptic neurons by alleviating a tonic inhibition mediated by $5-\mathrm{HT}$, but also enables a shift in endogenous 5-HT transmission toward activation of the $5-\mathrm{HT}_{4} \mathrm{R}$ and downstream signaling cascades 

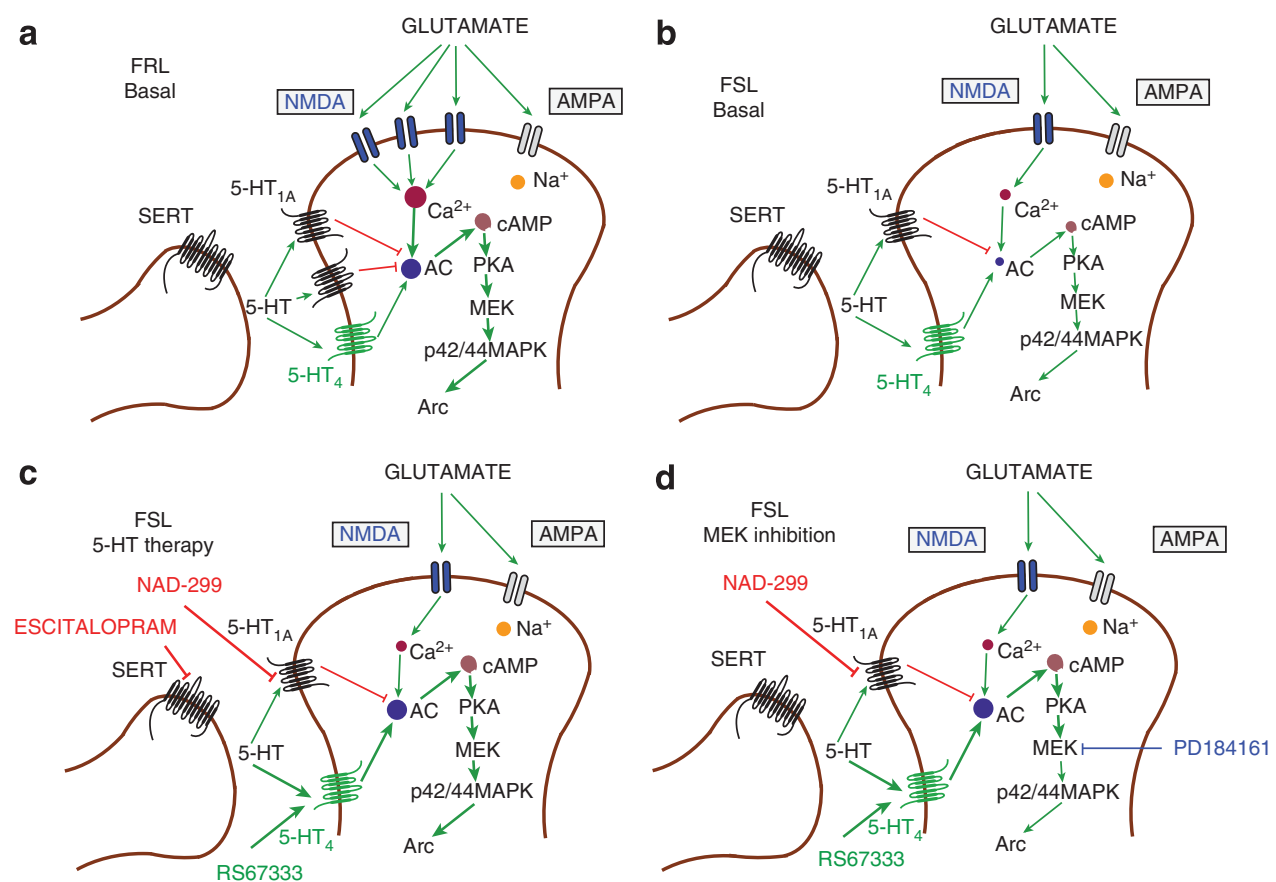

Figure 5 Schematic representation of mechanisms involved in effects on emotional memory function and stimulation of Arc transcription. Basal level of transmission in control Flinders resistant line (FRL) rats (a). Baseline transmission in untreated Flinders sensitive line (FSL) rats (b). The 5-HT therapy restores emotional memory disturbances and increases Arc transcription (c). Pretreatment with a MEK inhibitor blocks the restoring effects of pharmacological 5-HT therapy on memory performance and expression of Arc mRNA (d). See text besides respective figures for further details.

(Figure 5c). The effects of chronic SSRI administration on PA performance and Arc mRNA were thus replicated by either $5-\mathrm{HT}_{1 \mathrm{~A}} \mathrm{R}$ antagonism or $5-\mathrm{HT}_{4} \mathrm{R}$ agonism (Figures 4a, d, f and h), further supporting that central $5-\mathrm{HT}_{4} \mathrm{R}$ stimulation offers a potential target for improvement of emotional ${ }^{16}$ and cognitive processing. ${ }^{17}$

Systemic pretreatment with the MEK inhibitor PD184161 fully blocked the ability of both NAD-299 and RS67333 to restore memory function (Figure 4a) and induce Arc mRNA expression (Figures 4e, g and $h$ ). These data implicate an involvement of the MAPK signaling pathway as a nodal point in restoration of emotional memory consolidation. There is support for $\mathrm{G}_{\mathrm{i} / \mathrm{o}}$-protein- and $\mathrm{G}_{\mathrm{s}}$-protein-mediated receptor modulation of the MEK/MAPK cascade., ${ }^{9,23,48-50,73}$ Local increase of cyclic adenosine monophosphate (cAMP) may trigger events that are involved in induction of short-term plasticity and early stages of memory formation, whereas activation of MAPK signaling pathways may result in more long-lasting effects requiring nuclear gene transcription. ${ }^{21,23}$ Besides, fear conditioning and long-term potentiation-mediated increase of Arc expression in the lateral amygdala is dependent on activation of the MAPK cascade, ${ }^{74}$ and hippocampal cAMP/MAPK signaling is involved in long-term consolidation of contextual fear conditioning. ${ }^{75}$ Collectively, these findings emphasize a crucial involvement of the MEK/MAPK cascade as a nodal point in 5$\mathrm{HT}_{1 \mathrm{~A}} \mathrm{R} / 5-\mathrm{HT}_{4} \mathrm{R}$-mediated effects on emotional memory and expression of Arc mRNA (Figure 5d).
In conclusion, emotional memory impairments and baseline reductions of Arc transcription were found in the FSL rat line of depression. Memory functions and enhancement of Arc transcription were specifically induced by escitalopram and pharmacological treatments, increasing postsynaptic 5-HT function via stimulation of cAMP/MAPK signaling cascades. The FSL rat line provides a preclinical model recapitulating reversible deficits of cognitive processing that is disrupted in depression.

\section{Conflict of interest}

The authors declare no conflict of interest.

\section{Acknowledgments}

This work was supported by the Swedish Research Council, Swedish Royal Academy of Sciences, Söderberǵs stiftelse, Swedish Brain Fund and Karolinska Institute Faculty Funds (KID) (TME). We thank Dr Xiaoqun Zhang, Dr Hongshi Qi, Serena Balasso and Eleonora Tandoi for excellent experimental support.

\section{References}

1 Agid Y, Buzsáki G, Diamond DM, Frackowiak R, Giedd J, Girault JA et al. How can drug discovery for psychiatric disorders be improved? Nat Rev Drug Discov 2007; 3: 189-201. 
2 Clark L, Chamberlain SR, Sahakian BJ. Neurocognitive mechanisms in depression: implications for treatment. Annu Rev Neurosci 2009; 32: 57-74.

3 Montgomery SA. Why do we need new and better antidepressants? Int Clin Psychopharmacol 2006; 21(Suppl 1): S1-S10.

4 Harmer CJ. Serotonin and emotional processing: does it help explain antidepressant drug action? Neuropharmacology 2008; 55: 1023-1028.

5 McEwen BS, Chattarji S, Diamond DM, Jay TM, Reagan LP, Svenningsson $\mathrm{P}$ et al. The neurobiological properties of tianeptine (Stablon): from monoamine hypothesis to glutamatergic modulation. Mol Psychiatry 2010; 15: 237-249.

6 MacQueen GM, Campbell S, McEwen BS, Macdonald K, Amano S, Joffe RT et al. Course of illness, hippocampal function, and hippocampal volume in major depression. Proc Natl Acad Sci USA 2003; 100: 1387-1392.

7 Neumeister A, Wood S, Bonne O, Nugent AC, Luckenbaugh DA, Young $\mathrm{T}$ et al. Reduced hippocampal volume in unmedicated, remitted patients with major depression versus control subjects. Biol Psychiatry 2005; 57: 935-937.

8 Roiser JP, Levy J, Fromm SJ, Nugent AC, Talagala SL, Hasler G et al. The effects of tryptophan depletion on neural responses to emotional words in remitted depression. Biol Psychiatry 2009; 66: $441-450$.

9 Ogren SO, Eriksson TM, Elvander-Tottie E, D’Addario C, Ekström JC, Svenningsson $\mathrm{P}$ et al. The role of 5-HT(1A) receptors in learning and memory. Behav Brain Res 2008; 195: 54-77.

10 Arango V, Underwood MD, Boldrini M, Tamir H, Kassir SA, Hsiung $\mathrm{S}$ et al. Serotonin ${ }_{1 \mathrm{~A}}$ receptors, serotonin transporter binding and serotonin transporter mRNA expression in the brainstem of depressed suicide victims. Neuropsychopharmacology 2001; 25: 892-903.

11 Bhagwagar Z, Rabiner EA, Sargent PA, Grasby PM, Cowen PJ. Persistent reduction in brain serotonin1A receptor binding in recovered depressed men measured by positron emission tomography with WAY-100635. Mol Psychiatry 2004; 9: 386-392.

12 Borg J. Molecular imaging of the 5-HT(1A) receptor in relation to human cognition. Behav Brain Res 2008; 195: 103-111.

13 Hirvonen J, Karlsson H, Kajander J, Lepola A, Markkula J, RasiHakala $\mathrm{H}$ et al. Decreased brain serotonin 5-HT1A receptor availability in medication-naive patients with major depressive disorder: an in-vivo imaging study using PET and [carbonyl11C]WAY-100635. Int J Neuropsychopharmacol 2008; 11: 465-476.

14 Savitz J, Lucki I, Drevets WC. 5-HT(1A) receptor function in major depressive disorder. Prog Neurobiol 2009; 88: 17-31.

15 Stockmeier CA, Howley E, Shi X, Sobanska A, Clarke G, Friedman $\mathrm{L}$ et al. Antagonist but not agonist labeling of serotonin-1A receptors is decreased in major depressive disorder. J Psychiatr Res 2009; 43: 887-894.

16 Lucas G, Rymar VV, Du J, Mnie-Filali O, Bisgaard C, Manta S et al. Serotonin(4) (5-HT(4)) receptor agonists are putative antidepressants with a rapid onset of action. Neuron 2007; 55: 712-725.

17 Fontana DJ, Daniels SE, Wong EH, Clark RD, Eglen RM. The effects of novel, selective 5-hydroxytryptamine (5-HT)4 receptor ligands in rat spatial navigation. Neuropharmacology 1997; 36: 689-696.

18 Rantamäki T, Hendolin P, Kankaanpää A, Mijatovic J, Piepponen P, Domenici $\mathrm{E}$ et al. Pharmacologically diverse antidepressants rapidly activate brain-derived neurotrophic factor receptor TrkB and induce phospholipase-Cgamma signaling pathways in mouse brain. Neuropsychopharmacology 2007; 32: 2152-2162.

19 Saarelainen T, Hendolin P, Lucas G, Koponen E, Sairanen M, MacDonald E et al. Activation of the TrkB neurotrophin receptor is induced by antidepressant drugs and is required for antidepressant-induced behavioral effects. J Neurosci 2003; 23: 349-357.

20 Martinowich K, Manji H, Lu B. New insights into BDNF function in depression and anxiety. Nat Neurosci 2007; 10: 1089-1093.

21 Pittenger C, Duman RS. Stress, depression, and neuroplasticity: a convergence of mechanisms. Neuropsychopharmacology 2008; 33 : 88-109.

22 Huang EJ, Reichardt LF. Trk receptors: roles in neuronal signal transduction. Annu Rev Biochem 2003; 72: 609-642.

23 Stork PJ, Schmitt JM. Crosstalk between cAMP and MAP kinase signaling in the regulation of cell proliferation. Trends Cell Biol 2002; 12: 258-266.

24 Duman CH, Schlesinger L, Kodama M, Russell DS, Duman RS. A role for MAP kinase signaling in behavioral models of depression and antidepressant treatment. Biol Psychiatry 2007; 61: 661-670.

25 Yuan LL, Adams JP, Swank M, Sweatt JD, Johnston D. Protein kinase modulation of dendritic $\mathrm{K}+$ channels in hippocampus involves a mitogen-activated protein kinase pathway. J Neurosci 2002; 22: 4860-4868.

26 Bramham CR, Worley PF, Moore MJ, Guzowski JF. The immediate early gene arc/arg3.1: regulation, mechanisms, and function. J Neurosci 2008; 28: 11760-11767.

27 Panja D, Dagyte G, Bidinosti M, Wibrand K, Kristiansen AM, Sonenberg $\mathrm{N}$ et al. Novel translational control in Arc-dependent long term potentiation consolidation in vivo. J Biol Chem 2009; 284: 31498-31511.

28 Rao VR, Pintchovski SA, Chin J, Peebles CL, Mitra S, Finkbeiner S. AMPA receptors regulate transcription of the plasticity-related immediate-early gene Arc. Nat Neurosci 2006; 7: 887-895.

29 Steward O, Worley PF. Selective targeting of newly synthesized Arc mRNA to active synapses requires NMDAR activation. Neuron 2001; 30: 227-240.

30 Montag-Sallaz M, Montag D. Learning-induced arg 3.1/arc mRNA expression in the mouse brain. Learn Mem 2003; 10: 99-107.

31 Plath N, Ohana O, Dammermann B, Errington ML, Schmitz D, Gross C et al. Arc/Arg3.1 is essential for the consolidation of synaptic plasticity and memories. Neuron 2006; 52: 437-444.

32 Waltereit R, Dammermann B, Wulff P, Scafidi J, Staubli U, Kauselmann G et al. Arg3.1/Arc mRNA induction by $\mathrm{Ca} 2+$ and cAMP requires protein kinase $\mathrm{A}$ and mitogen-activated protein kinase/extracellular regulated kinase activation. J Neurosci 2001; 21: 5484-5493.

33 Tordera R, Pei Q, Newson M, Gray K, Sprakes M, Sharp T. Effect of different 5-HT1A receptor antagonists in combination with paroxetine on expression of the immediate-early gene Arc in rat brain. Neuropharmacology 2003; 44: 893-902.

34 Overstreet DH, Friedman E, Mathé AA, Yadid G. The Flinders Sensitive Line rat: a selectively bred putative animal model of depression. Neurosci Biobehav Rev 2005; 29: 739-759.

35 Tfilin M, Sudai E, Merenlender A, Gispan I, Yadid G, Turgeman G. Mesenchymal stem cells increase hippocampal neurogenesis and counteract depressive-like behavior. Mol Psychiatry 2010; 15: 1164-1175.

36 Ryan B, Musazzi L, Mallei A, Tardito D, Gruber SH, El Khoury A et al. Remodelling by early-life stress of NMDA receptordependent synaptic plasticity in a gene-environment rat model of depression. Int J Neuropsychopharmacol 2009; 12: 553-559.

37 Chen F, Madsen TM, Wegener G, Nyengaard JR. Imipramine treatment increases the number of hippocampal synapses and neurons in a genetic animal model of depression. Hippocampus 2010; 20: 1376-1384.

38 El Khoury A, Gruber SH, Mørk A, Mathé AA. Adult life behavioral consequences of early maternal separation are alleviated by escitalopram treatment in a rat model of depression. Prog Neuropsychopharmacol Biol Psychiatry 2006; 30: 535-540.

39 Petersén A, Wörtwein G, Gruber SH, El-Khoury A, Mathé AA. Nortriptyline mediates behavioral effects without affecting hippocampal cytogenesis in a genetic rat depression model. Neurosci Lett 2009; 451: 148-151.

40 Eglen RM, Bonhaus DW, Johnson LG, Leung E, Clark RD. Pharmacological characterization of two novel and potent 5HT4R agonists, RS 67333 and RS 67506, in vitro and in vivo. Br J Pharmacol 1995; 115: 1387-1392.

41 Lüttgen M, Elvander E, Madjid N, Ogren SO. Analysis of the role of 5-HT1A receptors in spatial and aversive learning in the rat. Neuropharmacology 2005; 48: 830-852.

42 Svenningsson P, Le Moine C, Aubert I, Burbaud P, Fredholm BB, Bloch B. Cellular distribution of adenosine A2A receptor mRNA in the primate striatum. J Comp Neurol 1998; 399: 229-240.

43 Svenningsson P, Chergui K, Rachleff I, Flajolet M, Zhang X, El Yacoubi $\mathrm{M}$ et al. Alterations in 5-HT1B receptor function by p11 in depression-like states. Science 2006; 311: 77-80.

44 Monyer H, Burnashev N, Laurie DJ, Sakmann B, Seeburg PH. Developmental and regional expression in the rat brain and functional properties of four NMDA receptors. Neuron 1994; 12: 529-540. 
45 Shimizu E, Tang YP, Rampon C, Tsien JZ. NMDA receptordependent synaptic reinforcement as a crucial process for memory consolidation. Science 2000; 290: 1170-1174.

46 Krapivinsky G, Krapivinsky L, Manasian Y, Ivanov A, Tyzio R, Pellegrino $\mathrm{C}$ et al. The NMDA receptor is coupled to the ERK pathway by a direct interaction between NR2B and RasGRF1. Neuron 2003; 40: 775-784.

47 Misane I, Ogren SO. Effects of Hypericum perforatum (St. John's wort) on passive avoidance in the rat: evaluation of potential neurochemical mechanisms underlying its antidepressant activity. Pharmacopsychiatry 2001; 34: S89-S97.

48 Garnovskaya MN, van Biesen T, Hawe B, Casanas Ramos S, Lefkowitz RJ, Raymond JR. Ras-dependent activation of fibroblast mitogen-activated protein kinase by 5 -HT1AR via a $\mathrm{G}$ protein beta gamma-subunit-initiated pathway. Biochemistry 1996; 35: 13716-13722.

49 Huang YY, Kandel ER. 5-Hydroxytryptamine induces a protein kinase $\mathrm{A} /$ mitogen-activated protein kinase-mediated and macromolecular synthesis-dependent late phase of long-term potentiation in the amygdala. J Neurosci 2007; 27: 3111-3119.

50 Norum JH, Hart K, Levy FO. Ras-dependent ERK activation by the human $\mathrm{G}(\mathrm{s})$-coupled serotonin receptors 5-HT4(b) and 5-HT7(a). J Biol Chem 2003; 278: 3098-3104.

51 Frodl T, Schaub A, Banac S, Charypar M, Jäger M, Kümmler P et al. Reduced hippocampal volume correlates with executive dysfunctioning in major depression. J Psychiatry Neurosci 2006; 31: 316-323.

52 Pfennig A, Littmann E, Bauer M. Neurocognitive impairment and dementia in mood disorders. J Neuropsychiatry Clin Neurosci 2007; 4: 373-382.

53 Maya Vetencourt JF, Sale A, Viegi A, Baroncelli L, De Pasquale R, O'Leary OF et al. The antidepressant fluoxetine restores plasticity in the adult visual cortex. Science 2008; 320: 385-388.

54 Miyashita T, Kubik S, Haghighi N, Steward O, Guzowski JF. Rapid activation of plasticity-associated gene transcription in hippocampal neurons provides a mechanism for encoding of one-trial experience. J Neurosci 2009; 29: 898-906.

55 Hashimoto K. Emerging role of glutamate in the pathophysiology of major depressive disorder. Brain Res Rev 2009; 61: 105-123.

56 Sanacora G, Zarate CA, Krystal JH, Manji HK. Targeting the glutamatergic system to develop novel, improved therapeutics for mood disorders. Nat Rev Drug Discov 2008; 7: 426-437.

57 Sanacora G, Gueorguieva R, Epperson CN, Wu YT, Appel M, Rothman DL et al. Subtype-specific alterations of $\gamma$-aminobutyric acid and glutamate in patients with major depression. Arch Gen Psychiatry 2004; 61: 705-713.

58 Hasler G, van der Veen JW, Tumonis T, Meyers N, Shen J, Drevets WC. Reduced prefrontal glutamate/glutamine and $\gamma$-aminobutyric acid levels in major depression determined using proton magnetic resonance spectroscopy. Arch Gen Psychiatry 2007; 64: 193-200.

59 Auer DP, Pütz B, Kraft E, Lipinski B, Schill J, Holsboer F. Reduced glutamate in the anterior cingulate cortex in depression: an in vivo proton magnetic resonance spectroscopy study. Biol Psychiatry 2000; 47: 305-313.

60 Nudmamud-Thanoi S, Reynolds GP. The NR1 subunit of the glutamate/NMDA receptor in the superior temporal cortex in schizophrenia and affective disorders. Neurosci Lett 2004; 372: 173-177.
61 Nowak G, Ordway GA, Paul IA. Alterations in the $N$-methyl-daspartate (NMDA) receptor complex in the frontal cortex of suicide victims. Brain Res 1995; 675: 157-164.

62 Feyissa AM, Chandran A, Stockmeier CA, Karolewicz B. Reduced levels of NR2A and NR2B subunits of NMDA receptor and PSD-95 in the prefrontal cortex in major depression. Prog Neuropsychopharmacol Biol Psychiatry 2009; 33: 70-75.

63 Beneyto M, Meador-Woodruff JH. Lamina-specific abnormalities of NMDA receptor-associated postsynaptic protein transcripts in the prefrontal cortex in schizophrenia and bipolar disorder. Neuropsychopharmacology 2008; 33: 2175-2186.

64 Beneyto M, Kristiansen LV, Oni-Orisan A, McCullumsmith RE, Meador-Woodruff JH. Abnormal glutamate receptor expression in the medial temporal lobe in schizophrenia and mood disorders. Neuropsychopharmacology 2007; 32: 1888-1902.

65 Lau CG, Zukin RS. NMDA receptor trafficking in synaptic plasticity and neuropsychiatric disorders. Nat Rev Neurosci 2007; 8: 413-426.

66 Nishi K, Kanemaru K, Hasegawa S, Watanabe A, Diksic M. Both acute and chronic buspirone treatments have different effects on regional 5-HT synthesis in Flinders Sensitive Line rats (a rat model of depression) than in control rats. Neurochem Int 2009; 54: 205-214.

67 Hindmarch I. Cognitive toxicity of pharmacotherapeutic agents used in social anxiety disorder. Int J Clin Pract 2009; 63: 1085-1094.

68 Uher R, Maier W, Hauser J, Marusic A, Schmael C, Mors O et al. Differential efficacy of escitalopram and nortriptyline on dimensional measures of depression. Br J Psychiatry 2009; 194: 252-259.

69 Castrén E, Rantamäki T. The role of BDNF and its receptors in depression and antidepressant drug action: reactivation of developmental plasticity. Dev Neurobiol 2010; 70: 289-297.

70 Jeanneteau F, Chao MV. Promoting neurotrophic effects by GPCR ligands. Novartis Found Symp 2006; 276: 181-189.

71 Minichiello L, Calella AM, Medina DL, Bonhoeffer T, Klein R, Korte M. Mechanism of TrkB-mediated hippocampal long-term potentiation. Neuron 2002; 36: 121-137.

72 Holick KA, Lee DC, Hen R, Dulawa SC. Behavioral effects of chronic fluoxetine in BALB/cJ mice do not require adult hippocampal neurogenesis or the serotonin 1A receptor. Neuropsychopharmacology 2008; 33: 406-417.

73 Chen J, Shen C, Meller E. 5-HT1A receptor-mediated regulation of mitogen-activated protein kinase phosphorylation in rat brain. Eur J Pharmacol 2002; 452: 155-162.

74 Ploski JE, Pierre VJ, Smucny J, Park K, Monsey MS, Overeem KA et al. The activity-regulated cytoskeletal-associated protein (Arc/Arg3.1) is required for memory consolidation of pavlovian fear conditioning in the lateral amygdala. J Neurosci 2008; 28: 12383-12395.

75 Eckel-Mahan KL, Phan T, Han S, Wang H, Chan GC, Scheiner ZS et al. Circadian oscillation of hippocampal MAPK activity and cAmp: implications for memory persistence. Nat Neurosci 2008; 11: 1074-1082.

This work is licensed under the Creative Commons Attribution-NonCommercialNo Derivative Works 3.0 Unported License. To view a copy of this license, visit http://creativecommons. org/licenses/by-nc-nd/3.0/

Supplementary Information accompanies the paper on the Molecular Psychiatry website (http://www.nature.com/mp) 